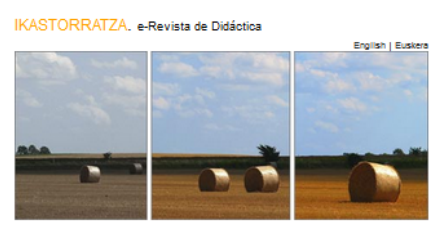

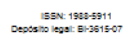

Inicio, Sobre nosotros, Publicacionesı, Participa

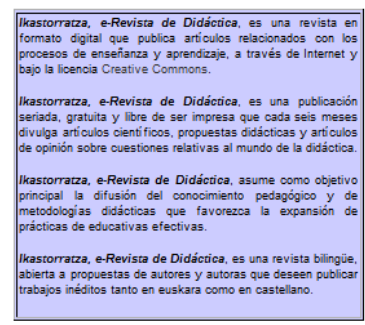

\section{IKASTORRATZA. Didaktikarako e-aldizkaria}

\author{
IKASTORRATZA. e-journal on Didactics
}

ISSN: 1988-5911 (Online) Journal homepage: http://www.ehu.eus/ikastorratza/

\title{
Vitalización y reproducción de la lengua Nasa Yuwe: dos modelos educativos en un contexto sociolingüístico minorizado
}

\author{
IKASTORRATZA. e-Revista de \\ Didáctica
}

\begin{abstract}
Amelia Benito del Valle Eskauriaza
Universidad del País Vasco/Euskal Herriko Unibertsitatea (UPV/EHU), Leioa amelia.benitodevalle@ehu.eus
\end{abstract}

To cite this article:

del Valle Eskauriaza, A. B. (2020). Vitalización y reproducción de la lengua Nasa Yuwe: dos modelos educativos en un contexto sociolingüístico minorizado. IKASTORRATZA. e-Revista de Didáctica, 24, 102-137. DOI: 10.37261/24_alea/5

To link to this article:

https://doi.org/10.37261/24_alea/5

Published online: 30 Abril 2020 


\title{
Vitalización y reproducción de la lengua Nasa Yuwe: dos modelos educativos en un contexto sociolingüístico minorizado.
}

\author{
Amelia Benito del Valle Eskauriaza \\ Universidad del País Vasco/Euskal Herriko Unibertsitatea (UPV/EHU) \\ amelia.benitodevalle@ehu.eus
}

\section{Resumen}

La UNESCO ha declarado el 2019 como “Año Internacional de las Lenguas Indígenas” brindando una ocasión a los diferentes países y naciones a impulsar la lengua, cultura e identidad de los pueblos indígenas que habitan sus territorios. En Colombia las lenguas indígenas se encuentran en un proceso de ser revitalizadas ante la pérdida de hablantes. Una de estas lenguas es la Nasa Yuwe. Así pues, a través de las siguientes páginas, tras una estancia sobre el terreno, se realiza un análisis de los procesos de revitalización de la cultura Nasa y de la lengua Nasa Yuwe, en el resguardo de Tóez Caloto, con el fin de verificar y comprender los dos modelos educativos ubicados en el mismo.

Palabras clave: Nasa, Nasa Yuwe, revitalizar, educación, Buçxujx we’weka kwe’sx Yuwe’s o Nido lingüístico

\section{Laburpena}

2019, Nazio Batuen Elkarteak "Hizkuntza Indigenen Nazioarteko Urtea” izendatu du.. UNESCOk herrialde eta nazio desberdinetarako aukera eskaintzen du lurraldeetako indigenen hizkuntza, kultura eta identitatea sustatzeko. Kolonbian, hizkuntza indigenek biziberritzea behar dute hiztunen asko galtzen dutelako. Hizkuntza horietako bat Nasa Yuwe da. Horrela, ondorengo orrialdeen bidez, Nasa kulturaren eta Nasa Yuwe hizkuntzaren biziberritze prozesuetara hurbiltzea xedea da Calo-Tóezen dauden bi hezkuntza eredutara aztertzen.

Hitz gakoa: Nasa, Nasa Yuwe, biziberritu, hezkunzta, Buçxujx we’weka kwe’sx Yuwe’s ala Bizitoki linguistikoa 


\begin{abstract}
UNESCO has declared 2019 as the "International Year of Indigenous Languages" providing an opportunity for different countries to promote the language, culture and identity of the indigenous peoples of their respective territories. In Colombia, indigenous languages find themselves in a fragile situation due to the innumerable loss of speakers, and thus, in need of revitalization. One of these languages is Nasa Yuwe. The following pages take a closer look at the various revitalization processes of both the Nasa culture and the Nasa Yuwe language on the Tóez Caloto Reservation in order to analyze the two educational models found there.
\end{abstract}

Key words : Nasa, Nasa Yuwe, revitalization, education, Buçxujx we'weka kwe'sx Yuwe's or Linguistic nest 


\section{Introducción}

Durante el año 2019 la UNESCO ha proclamado el “Año Internacional de las Lenguas Indígenas” y con ello ha querido recordar que la lengua no es sólo un instrumento de comunicación, sino también una herramienta que define la identidad, que expresa la historia y muestra la cultura de un pueblo ${ }^{1}$. Las diferentes lenguas existentes permiten participar en el entramado social de una comunidad determinada, ayudan a preservar la historia, las costumbres, la memoria y las formas de pensamiento, significado y expresión. Igualmente, el derecho a usar la lengua propia es un requerimiento previo para la libertad de pensamiento, de opinión y de expresión.

Además de todo ello, la UNESCO, señala que las lenguas indígenas son la clave para el desarrollo de las comunidades, la protección de los derechos humanos, la salvaguarda de la consolidación de la paz y la reconciliación de los pueblos.

Por ello, 2019 quiere ser una llamada a la toma de conciencia sobre la situación en la que se encuentran miles de lenguas en el mundo. Según la UNESCO, de las casi 7.000 lenguas existentes, la mayoría de las mismas son habladas por pueblos indígenas, lo que representa la mayor parte de la diversidad cultural del mundo. La acelerada desaparición de estas lenguas y de su soporte cultural, debido a múltiples factores, como por ejemplo las reubicaciones forzadas, el analfabetismo y la pobreza, entre otros, ha llevado a la Organización de las Naciones Unidas para la Educación, la Ciencia y la Cultura $\left(\mathrm{UNESCO}^{2}\right.$ ) a “alentar” a los diferentes países a adoptar medidas urgentes para “preservar, revitalizar y promover” el uso de estas lenguas indígenas.

Este año “dedicado a producir cambios"3, en cuanto a la toma de conciencia de los Estados y la supervivencia de las lenguas indígenas, es clave para profundizar en los contextos sociolingüísticos minorizados y en la dificultad que tienen sus miembros para poder participar socialmente en su propia lengua. Igualmente, la "Declaración de las Naciones Unidas sobre los Derechos de los Pueblos Indígenas” y los objetivos recogidos

\footnotetext{
${ }^{1}$ UNESCO. (S.F.) (2019). Recuperado de https://uploadsssl.webflow.com/5d2499e6a5dbeca3c357d762/5d9caaaacedb8f04ef2e661d_ES_ UNESCO-A.pdf

${ }^{2}$ Para más información consultar: Permanent Forum on Indigenous Issues. (2017). https://www.un.org/development/desa/indigenouspeoples/unpfii-sessions-2/sixteenthsession.html

${ }^{3}$ Ibid
} 
en “la Agenda 2030 para el Desarrollo Sostenible” remarcan esta necesidad. Así, este año en curso, es una apelación para recordar la necesidad de mantener las lenguas indígenas y su universo cultural y social. Por ello, en este artículo, se tratará desde el enfoque académico poner de relieve aquellos factores socioculturales que de alguna manera “limitan” el contexto sociolingüístico en la reproducción de la lengua Nasa Yuwe en el reguardo de Tóez, Caloto, Colombia. Es decir, este artículo tiene como objetivo, por un lado hacer una llamada a la reflexión sobre el estado actual del Nasa Yuwe en el resguardo de Tóez, Caloto. Por otro, evidenciar cuál es el modelo educativo, de los dos existentes en la actualidad en el resguardo, que mejor se adecua a las necesidades de revitalización de la lengua en el contexto socio-cultural actual del mismo.

Así pues, en las siguientes páginas y coincidiendo con “el Año Internacional de Las Lenguas Indígenas”, así como la estancia de investigación y la aportación de conocimientos mutuos, realizada por la autora del presente artículo en la "Comunidad Indígena Nasa, de Tóez, Caloto” en Colombia, se reflexiona sobre la experiencia vivida en un contexto sociolingüístico indígena. Primeramente y a través del marco teórico se hará un recorrido sobre la normativa centrada en el estatuto de la lengua Nasa Yuwe como parte integrante de las lenguas indígenas colombianas. Para ello, se mencionará la situación sociolingüística de Colombia. A continuación, se mostrará una concisa panorámica sobre el pueblo Nasa y la lengua Nasa Yuwe. Seguidamente, se pondrá el acento en el resguardo de Tóez, Caloto, para llevar a cabo una reflexión sobre la complejidad de la reproducción de la lengua Nasa Yuwe en "su micro contexto sociolingüístico” analizando la conciencia sociolingüística (Etxebarria, 2000) y la actitud lingüística (Fishman, 1972). Posteriormente, se examinarán los dos modelos educativos del resguardo de Tóez, Caloto, a través de técnicas de recogida de datos cualitativas, para finalmente desarrollar los resultados obtenidos y las conclusiones.

\section{Marco Teórico}

La lengua Nasa Yuwe hace parte del conjunto de las lenguas indígenas existentes en Colombia. Por lo tanto, al igual que las demás, se rige por el estatuto de las lenguas indígenas de Colombia. Por ello, en este apartado, se detalla el estatuto de las lenguas indígenas, para posteriormente introducir al pueblo indígena Nasa, su lengua Nasa Yuwe 
y sus especificidades actuales. A continuación, se remarca el enfoque teórico de Etxebarria (2000) y Fishman (1972) sobre la conciencia sociolingüística y la actitud lingüística que se va a aplicar a la situación sociolingüística del resguardo de Tóez, Caloto y por último se ahonda en el propio resguardo y su organización educativa escolar.

\subsection{Estatuto de las lenguas indígenas en Colombia}

Se puede situar en la historia reciente de América Latina y más concretamente en la de Colombia, el reconocimiento oficial de las diferentes lenguas y culturas autóctonas que coexisten en el país. En la Constitución Política de Colombia de 1991 se reconoce la multiplicidad étnica y se autoriza a las comunidades indígenas a participar en la vida pública y política del país.

Sin embargo, no es hasta el año 2010, que la "Ley de derechos lingüísticos de Colombia” o "Ley 1381", pretende dotar de un marco de protección a la pluralidad de lenguas que se enmarcan dentro del territorio histórico colombiano. A partir de esta ley, se han ido desarrollando diferentes planes y estrategias de protección y fortalecimiento del gran abanico plural de lenguas del país. Desde la Dirección de Poblaciones del Ministerio de Cultura, se promueven acciones que intentan preservar el uso y mantenimiento de las lenguas nativas.

En el documento “Atención institucional del Estado a la protección de la diversidad etnolingüística en Colombia” publicado por la Dirección de Poblaciones del Ministerio de Cultura, se señala que además del español, el panorama lingüístico colombiano está compuesto por alrededor de 64 lenguas indígenas, dos lenguas criollas, la lengua romaní y la lengua de señas colombiana.

Según el último censo DANE ${ }^{4}$ (Departamento Administrativo Nacional de Estadística, 2018) en Colombia, se hablan 68 lenguas nativas. Las comunidades donde se desarrollan, conllevan un total de 850.000 personas. Estas lenguas se pueden subdividir en tres categorías: las de la región caribeña, las criollas y las de los pueblos Raizal y Palenqueros. Las indoeuropeas, como el rromanés o shib rromaní y sus variantes habladas por los

\footnotetext{
${ }^{4}$ A partir de ahora se utilizarán estas siglas para referirse al Departamento Administrativo Nacional de Estadística. DANE.
} 
pueblos rrom o gitano y las lenguas indoamericanas o indígenas, habladas por los autóctonos del territorio colombiano.

En 2018 el DANE ${ }^{5}$ se compromete con las diferentes organizaciones indígenas del país a implementar ${ }^{6}$ una serie de acuerdos a la hora de realizar sus cuestionarios estadísticos, incluyendo un enfoque étnico sobre las diferencias, en el Censo Nacional de Población y Vivienda. Sin embargo, en la encuesta realizada en este periodo, entre los indicadores que se producen a partir de la información censal no aparece ninguno referente a las lenguas de uso.

Por otro lado, ante la iniciativa del gobierno colombiano de querer salvaguardar el patrimonio lingüístico, la Dirección de Pobladores ${ }^{7}$ en 2008 creó una serie de espacios de diálogo cultural con las personas más representativas de cada comunidad indígena para la revitalización de las lenguas maternas. En el informe realizado en 2011, bajo el título “Auto-diagnóstico sociolingüístico” pone de relieve el estado de vitalidad de las lenguas nativas. Más recientemente, el Círculo de la Palabra Lenguas Nativas (2014) hace balance de la situación de las lenguas nativas, afirmando que es muy variada y depende de muchos factores:

La situación de las lenguas nativas es muy distinta, pues cada una de las mismas responde a realidades diferentes que obedecen a las condiciones sociales, demográficas, geográficas, económicas y culturales, que permean de diferentes maneras a las comunidades y por ende el contexto sociolingüístico de las mismas es diverso.

A pesar de la legalidad vigente y del breve desarrollo y recorrido institucional en favor de las lenguas nativas, la información aportada por las diferentes organizaciones y asociaciones, indica y profundiza en una dirección, en el de la insuficiencia. El estado de las lenguas nativas requiere de una implicación que abarque a todos los estamentos sociales en la búsqueda y puesta en práctica de una política y planificación

\footnotetext{
${ }^{5}$ Todavía no se han publicado los resultados de estas encuestas

${ }^{6}$ DANE (2019). Recuperado de https://www.dane.gov.co/index.php/actualidad-dane/4464-eldane-reitera-su-compromiso-con-las-organizaciones-indigenas

7 "En el 2008 fue creada la Dirección de Poblaciones del Ministerio de Cultura, con el propósito de orientar e implementar políticas, programas y proyectos que permitan avanzar en el entendimiento de la cultura como parte integral del desarrollo de nuestra nación.” Ministerio de Cultura de Colombia. (2919). Recuperado de https://www.dane.gov.co/index.php/actualidaddane/4464-el-dane-reitera-su-compromiso-con-las-organizaciones-indigenas
} 
sociolingüística. Por ello, para dotar a una lengua de un futuro de supervivencia y reproducción, es necesario tener en cuenta, tanto el actual, como el histórico, marco sociocultural y económico de su evolución o involución.

En el conjunto de las lenguas históricamente marginadas y en amplio riesgo de desaparición se encuentra la lengua Nasa Yuwe. El caso de la lengua Nasa Yuwe, hablada por el pueblo Nasa, es similar al de las otras lenguas minorizadas y minoritarias del amplio espectro lingüístico colombiano.

\subsection{El pueblo Nasa}

Actualmente, el pueblo Nasa se sitúa geográficamente en distintos emplazamientos llamados “resguardos”. Al término resguardo hay que sumarle el vocablo “indígena”, es decir los conceptos "resguardo e indígena” van fusionados y adquieren su valor social, cultural, político y económico en esta unidad. Por lo tanto, hay que entender que un “Resguardo Indígena” es una institución legal sociopolítica. Esta institución está conformada por un territorio perteneciente a una comunidad de origen amerindio. Además, esta comunidad es propietaria de ese espacio geográfico y se rige por un estatuto autónomo siguiendo las tradiciones culturales propias. En 2013 Susana Betancourt define de esta manera los resguardos indígenas:

Los resguardos indígenas son propiedad colectiva de las comunidades indígenas a favor de las cuales se constituyen y conforme a los artículos 63 y 329 de la Constitución Política, tienen el carácter de inalienables, imprescriptibles e inembargables. Los resguardos indígenas son una institución legal y sociopolítica de carácter especial, conformada por una o más comunidades indígenas, que con un título de propiedad colectiva que goza de las garantías de la propiedad privada, poseen su territorio y se rigen para el manejo de éste y su vida interna por una organización autónoma amparada por el fuero indígena y su sistema normativo propio (Artículo 21, decreto 2164 de 1995). ${ }^{8}$

Por la tanto, el pueblo Nasa, se asienta en diferentes resguardos indígenas localizados en distintos puntos geográficos. Para comprender esta división del pueblo Nasa conviene realizar una breve mirada a la formación del territorio colombiano cuyos amerindios Nasa

\footnotetext{
${ }^{8}$ Susana Betancourt. (2013). Recuperado de https://www.mininterior.gov.co/content/resguardoindigena
} 
han habitado de "manera tradicional y dispersa, desde antes del siglo XVI, la zona conocida como Tierradentro” (Corrales, 2018).

Debido a diferentes razones históricas, de carácter conquistador-bélico, y más recientemente huyendo de los conflictos armados, desordenes climáticos y de supervivencia, el pueblo Nasa se ha visto desplazado de sus espacios geográficos ancestrales, moviéndose a diferentes lugares y territorios. Se puede considerar que en 1994, debido a un terremoto y sus consecuencias sobre el rio Páez, se produjo el último desplazamiento no voluntario del pueblo Nasa.

Tabla 1: Resumen de la configuración territorial y de la población indígena y Nasa.

\begin{tabular}{|c|c|}
\hline DEPARTAMENTOS & 32, Figura Administrativa Gobernador \\
\hline PROVINCIAS & $\begin{array}{l}\text { Es el nombre genérico que se aplica en algunas subdivisiones } \\
\text { internas de los departamentos }\end{array}$ \\
\hline MUNICIPIOS & 1123 URBANOS Y RURALES \\
\hline DISTRITOS & 5, administración especial por su importancia, ejemplo Bogotá. \\
\hline $\begin{array}{l}\text { ENTIDADES } \\
\text { TERRITORIALES } \\
\text { INDIGENAS }\end{array}$ & $\begin{array}{l}\text { Entidades Territoriales: los departamentos, distritos, municipios y } \\
\text { territorios indígenas (Art. 286); que gozan de autonomía para la } \\
\text { gestión de sus intereses; y dentro de los límites de la constitución } \\
\text { tienen derecho a administrar los recursos y establecer los tributos } \\
\text { necesarios para el cumplimiento de sus funciones (Art. 287). Siguen } \\
\text { sin reglamentar: } \\
\begin{array}{lll}\text { Legalidad. } \quad \text { (s.f.). Recuperado } \quad 5 \quad \text { octubre } \\
\text { http:/territorioindigenaygobernanza.com/web/bienvenidos/ }\end{array}\end{array}$ \\
\hline $\begin{array}{l}\text { TERRITORIOS } \\
\text { COLECTIVOS }\end{array}$ & $\begin{array}{l}\text { Resguardos indígenas } \\
\text { Comunidades afro-colombianas }\end{array}$ \\
\hline $\begin{array}{l}\text { COMUNIDADES } \\
\text { INDÍGENAS }\end{array}$ & ANE 2018) \\
\hline $\begin{array}{l}\text { PUEBLOS } \\
\text { INDÍGENAS } \\
\text { NATIVOS }\end{array}$ & $\begin{array}{l}115 \text { (Censo DANE } 2018 \text { Aumento con respecto al } 2005 \\
\text { Los } 22 \text { pueblos adicionales de } 2018 \text { corresponden a nuevos } \\
\text { reconocimientos étnicos o pueblos indígenas de zonas fronterizas. } \\
\text { Los pueblos indígenas en aislamiento voluntario, no han sido } \\
\text { censados (Decreto } 1232 \text { de 2018) }\end{array}$ \\
\hline $\begin{array}{l}\text { POBLACIÓN QUE } \\
\text { SE RECONOCE } \\
\text { COMO INDÍGENA }\end{array}$ & $\begin{array}{l}1.905 .617 \text { (Censo DANE 2018) Teniendo en cuenta el censo } \\
\text { realizado en } 2005 \text {, la población indígena ha aumentado un } 36,8 \%\end{array}$ \\
\hline $\begin{array}{l}\text { RESGUARDOS } \\
\text { INDÍGENAS }\end{array}$ & 710 resguardos ubicados en 27 departamentos y en 228 municipios \\
\hline $\begin{array}{l}\text { POBLACIÓN } \\
\text { NASA }\end{array}$ & 243. 176 (Censo DANE 2018) \\
\hline $\begin{array}{l}\text { RESGUARDOS } \\
\text { NASA }\end{array}$ & $\begin{array}{l}\text { Departamento Del Cauca } \\
\text { Departamento Del Huila } \\
\text { Departamento Del Valle } \\
\text { Departamento De Putumayo } \\
\text { Departamento De Caquetá } \\
\text { Departamento De Meta }\end{array}$ \\
\hline
\end{tabular}


Por lo tanto, en la actualidad, al referirse al pueblo Nasa hay que subrayar un modo de habitabilidad dispersa en diferentes departamentos y resguardos. Los amerindios Nasa ocupan territorios geográficos "resguardos indígenas" separados entre sí por la configuración territorial política de Colombia (ver tabla 1).

Como bien se puede observar en la anterior figura, según el censo DANE de 2018, la población Nasa asciende a 243.176 indígenas repartidos en resguardos que se extienden a lo largo de varios departamentos.

\subsection{La lengua Nasa Yuwe}

El pueblo Nasa es el que más población tiene después de las comunidades indígenas de Wayuu y Zenú. Sin embargo el número de amerindios pertenecientes a la cultura Nasa no es proporcional al número de hablantes de la lengua Nasa Yuwe. Tal y como se recoge en la tabla 1, la población Nasa es de 243. 176 personas. Sin embargo, teniendo en cuenta que los datos recogidos por el DANE en el "Censo Nacional de Población y Vivienda 2018 - Pueblos indígenas”, con respecto a la cantidad de indígenas de cada comunidad que habla su lengua, todavía no han sido publicados, se referirán aquí algunas de las fuentes consultadas. Así, según el Instituto Caro y Cuervo (2019) es complejo calcular el número de hablantes de la lengua Nasa:

Es difícil saber cuántas personas hablan su lengua materna, pero se calcula que alrededor de un $60 \%$ de la población páez $^{9}$ (Nasa) en la actualidad continúa utilizando su lengua materna en la cotidianidad.

Pachón, X. (1997) observa la gran dificultad de contabilizar el número de hablantes, dando la cifra de 60.000 personas. Raymond G. (2005) afirma que en el año 2000 había 77. 400. Por su lado, Jon Landaburu (2005) aporta la cifra de 100.000 hablantes. A su vez, Austin, P., en el año 2008, indica la existencia de 75.000 hablantes Nasa Yuwe. Según Garabide (2019) ${ }^{\mathbf{1 0}}$ el número de hablantes es de 75.000 aproximadamente. Es

\footnotetext{
${ }^{9}$ El pueblo Nasa, ha sido conocido también con el término páez. Otros términos utilizados son Naza Paéz - Nasa Yuwe, o "gente del agua, según el ONIC (2019) Organización Nacional Indígena de Colombia. En la investigación de campo realizada en el resguardo de Toez, Caloto (2019), los miembros entrevistados se referían continuamente a la cultura Nasa y lengua Nasa Yuwe.

${ }^{10}$ GARABIDE (2019) La Asociación Garabide es una Organización No Gubernamental que realiza cooperación de un modo novedoso. Más concretamente, en el ámbito de la cooperación,
} 
evidente, que habrá que esperar a la publicación de los datos del DANE 2018, sin embargo queriendo mantener la cautela en la variable numérica y teniendo en cuenta la miscelánea de las fuentes consultadas, se "puede mencionar" un porcentaje que oscila alrededor de un $60 \%$.

A pesar de la inexactitud numérica, lo que está claro es la preocupación existente en la comunidad Nasa por revitalizar la lengua propia ante la influencia de la lengua hegemónica y los aparatos de Estado que la refrendan. Así lo explicaba Jorge Inseca (2014), ex gobernador del Cabildo indígena de Tóez, en un acto realizado con las comunidades desplazadas por la avalancha del 6 de junio de 1.994:

... Veinte años después, los y las Nasas provenientes de la zona Tierra Dentro, denominada "la cuna ancestral del pueblo Nasa"; en un nuevo territorio han hecho camino, han reconstruido el pensamiento, la identidad y el proceso organizativo, sin embargo para hacer este camino han afrontado diversas amenazas una de ellas, la pérdida de identidad a causa de las ideologías modernas que llegan a través de la tecnología. "Niños que llegaron de Tóez Páez a Tóez Caloto hablando la lengua indígena Nasa Yuwe, ahora ya adultos no la hablan, porque después de levantar el plato de sancocho, lo primero que las familias compran es un televisor, la tecnología nos está cambiando el pensamiento.

En esta misma línea, el informe "Nasa Yuwe”, publicado por el gobierno colombiano a través de Mincultura, la Cultura es de Todos (2005) ${ }^{11}$, profundiza en la situación de la reducción del número de hablantes de esta lengua. Igualmente, pone el acento en la pérdida de las tradiciones y aspectos de su cultura, señalando que esta merma cultural y lingüística no se desarrolla de la misma manera en todas las comunidades Nasas. Los procesos de asimilación en lengua y cultura hegemónica, aunque avanzan de forma rápida y contundente, es desigual y diferente en los resguardos.

Corrales (2018) advierte del estado en que se encuentran las lenguas indígenas colombianas, entre las que se encuentra el Nasa Yuwe. Añade que el uso de las lenguas indígenas se viene debilitando y que estas "se encuentran en condiciones minoritarias, minorizadas, discriminadas y subvaloradas. Situación que las pone en alto riesgo y con grandes amenazas de morir”.

apoyan procesos de revitalización lingüística de lenguas minorizadas partiendo de la experiencia del euskera.

${ }^{11}$ Gobierno Colombiano a través de Mincultura, la Cultura es de Todos. (s.f.). (2019).

Recuperado de https://www.mincultura.gov.co/areas/poblaciones/APP-de-lenguasnativas/Documents/Estudios\%20Nasa\%20yuwe.pdf 
Dada la situación sociolingüística de la lengua Nasa Yuwe, así como la de las otras lenguas indígenas, se ponen en marcha una serie de programas y planes de “revitalecimiento" que se van a cimentar en tres ámbitos sociales (Corrales, 2018). Por un lado, el movimiento indígena que trabaja por una “Educación propia” (desde los años 70) asentada en su cultura, condiciones y necesidades. Por otro lado, el Estado colombiano, que de "alguna manera" trata de desarrollar una política sociocultural y lingüística acorde a la identidad de los pueblos indígenas. Y por último, "la academia, que desde los años 90 empezó a concebir y desarrollar la Etnoeducación como campo de investigación y formación profesional” (Corrales, 2018).

Si las primeras iniciativas para dotar a la lengua Nasa Yuwe de un corpus lingüístico surgen y se originan a partir de estamentos y organizaciones religiosas (Landaburu, J. 2005), la secularización de la investigación, análisis y producción de textos va a extenderse a otros estamentos sociales.

Al final de esa década de los sesenta, además de sus traducciones de textos religiosos bíblicos, empiezan a publicar estudios fonológicos y gramaticales sobre una treintena de lenguas” (Landaburu, J. 2005).

Tulio Rojas (2002) hace un extenso recorrido sobre los antecedentes histórico-sociales al explicar la formación de la escritura de la lengua Nasa Yuwe. Este investigador declara, que en 1964, llegó a la región de Pitayó, un grupo de misioneros del Instituto Lingüístico de Verano (ILV) que confiere a la lengua Nasa Yuwe de un sistema de escritura. Sistema que evidentemente obedece a intereses de evangelización colonizadora y que se basa en el alfabeto de la lengua hegemónica castellana. Como señala Rojas (2002) esta escritura apenas va a tener eco fuera de su ámbito religioso. Siguiendo con este mismo autor, añade, que un año más tarde, otro grupo de religiosos, esta vez católicos, el Instituto Misionero Antropológico (IMA), propone otro sistema de escritura, que debido a su complejidad, es inmediatamente retirado por los propios autores.

Antes de la unificación del alfabeto Nasa Yuwe, se origina una tercera propuesta, auspiciada por el CRIC, Consejo Regional Indígena del Cauca. Esta iniciativa estuvo vigente entre 1984 y 2000, llegándose a producir diferentes textos temáticos.

En esta dinámica el pueblo Nasa y el CRIC, deciden discutir las diferentes propuestas. Finalmente, en 2001, se presenta un alfabeto unificado con el lema "Sabiduría y pensamiento de pueblos que nos resistimos a desaparecer”. 
Esta Comisión presentó el alfabeto unificado de la lengua Nasa en el décimo primer Congreso Regional Indígena del Cauca, realizado en el resguardo La María del municipio de Piendamó, en marzo de 2001, en el que participaron más de 7000 Nasa, entre quienes estuvieron 81 gobernadores de Cabildos. Congreso en el que se aprobó este alfabeto unificado con el lema Sabiduría y pensamiento de pueblos que nos resistimos a desaparecer. Alfabeto que sigue en el 2011, continúa en proceso de socialización y apropiación en las diferentes regiones y comunidades Nasa, con el aval de las asociaciones de cabildos Nasa del departamento del Cauca. (Corrales, M. 2011)

Las distintas variedades del Nasa Yuwe pueden vehicularse a través del alfabeto unificado sin necesidad de ser obviadas. Estas variedades y su uso escrito son comprensibles para toda la comunidad Nasa, como así lo confirmaba una de las informadoras del resguardo de Tóez, entrevistada en abril de 2019. Esta persona afirmaba que "ella habla el dialecto de Tierradentro y que comprende perfectamente a cualquier otra persona que hable otro dialecto Nasa Yuwe”. Los diferentes dialectos Nasa, siempre según esta informadora, no son un impedimento en la expresión y comprensión oral, sino que mantienen, además, una cohesión en la competencia comunicativa en cualquier situación sociolingüística. Igualmente esta informadora, señalaba que la diversidad dialectal, "es una riqueza que no hay que perder”.

Sin embargo, Corrales, M. (2011), afirma que la existencia de un alfabeto unificado, siendo un gran aporte para esta lengua indígena Nasa Yuwe, se muestra insuficiente como garante de la supervivencia, fortalecimiento, vitalidad social, política y cognitiva de la misma.

Es evidente que, la formalización de un alfabeto común para todos los Nasa Yuwe hablantes es un paso adelante en el proceso de vitalidad de una lengua, pero tal y como señalan algunos investigadores (Rojas, T., Perdomo, A. Corrales, M. 2011) este proceso debe continuar.

La variable, alfabeto unificado en el caso del Nasa Yuwe, no se enraíza en la existencia de una estandarización de la lengua. Sin embargo, en el campo de la sociolingüística, toma gran relevancia las actividades relacionadas con las posiciones lingüísticas, las políticas y planes lingüísticos de una lengua en aras de su vitalización y capacidad de reproducción. 
Por ello a pesar de la "no existencia oficial” de una lengua Nasa Yuwe estandarizada sí se puede afirmar la presencia de indicios que apuntan hacia "una homogeneización” de ciertas variables de la lengua a través de la planificación lingüística, en este caso a través del alfabeto unificado. Igualmente, existen varios corpus lingüísticos que muestran la riqueza de las variantes dialectales. Sin embargo, Martha Corrales (2019), señala que aunque se han realizado estudios gramaticales, estos todavía son bastantes incompletos y que no se puede hablar de una gramática estandarizada. Además, en las instituciones educativas es muy poco lo que se enseña sobre el conjunto de normas para hablar y escribir una lengua. Por lo tanto, todo parece señalar la necesidad de seguir ahondando en la profundización de una planificación lingüística apropiada a todas las variantes habladas del Nasa Yuwe. Así, la vía de investigación queda abierta a “la necesidad” de aunar conceptos lingüísticos en su "totalidad" o en su "parcialidad". Al mismo tiempo, se pone de relieve la necesidad de ordenar, clasificar y archivar los innumerables productos de tipo lingüístico y cultural que últimamente están siendo publicados. En resumen, además de tener que seguir profundizando en el saber hacer lingüístico pragmático, también sería conveniente hacer un “diagnóstico” del material que se tiene, ordenándolo, clasificándolo, etcétera.

Por otro lado, teniendo en cuenta que una lengua evoluciona o involuciona en función del contexto socioeconómico y político en el que se encuentre, cabe pensar que la lengua Nasa Yuwe necesita refuerzos culturales, tanto basados en la tradición como en referentes más actuales para su reproducción y subsistencia. Así por ejemplo, si los y las personas mayores de esta comunidad siempre han transmitido historias a través de la oralidad, ¿por qué no organizar un concurso de "narradores y narradoras" que cuenten historias divertidas, en el que puedan participar personas de cualquier edad? O bien, organizar un concurso literario oral o escrito y promocionar a los y las ganadoras; o bien, organizar una minga deportiva para promocionar el uso del Nasa Yuwe, o bien “elevar” a categoría de cantantes algún grupo de jóvenes, por ejemplo. Es evidente que la planificación lingüística puede acompañarse de otro tipo de planificaciones, como en este caso la cultural.

Curiosamente, el núcleo simbólico tradicional de la cultura Nasa, a pesar de su pérdida paulatina, parece estar bastante estandarizada. Es decir, la gente de los diferentes resguardos comparte las mismas creencias, mitos y símbolos con algunas variaciones 
según las zonas. Igualmente, los espacios simbólicos parecen seguir presentes no solamente en el imaginario colectivo, tal es el caso de la casa, Nasa yat, y la tulpa, ipy kuejt. ¿Pero qué ocurre en el resguardo de Tóez, Caloto?

\subsection{Resguardo de Tóez, Caloto}

Según los datos de 2016 aportados por José Aldemar Inseca Pacho, gobernador y representante legal de Tóez ${ }^{12}$, el resguardo aunque es de propiedad colectiva está dividido en parcelas familiares y en una finca comunitaria. En cuanto a la población que la ocupa no es enteramente Nasa e integra 232 familias y 786 comuneros:

Figura 1: Población reguardo de Tóez. 2016

\section{RESGUARDO DE TÓEZ}

\section{8\% indígenas Nasa}

$1.2 \%$

mestizos
$0.8 \%$ indígenas

Guambianos

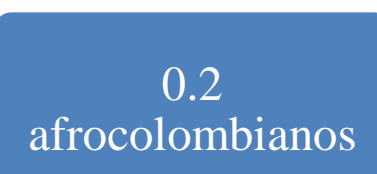

afrocolombianos

La mayoría de pobladores forman parte de la comunidad Nasa, siendo su cultura y lengua la predominante en el resguardo. Sin embargo, la convivencia de indígenas Nasa con guambianos, con afrocolombianos y mestizos en el espacio geográfico del resguardo, enmarca, de alguna manera, las relaciones sociales, los intercambios comerciales, culturales y lingüísticos en el uso de la lengua hegemónica de la sociedad colombiana.

\footnotetext{
${ }^{12}$ Dado que los últimos datos del DANE 2018 sobre los resguardos indígenas todavía no han sido publicados, se ha remitido al informe de José Aldemar Inseca Pacho (2016) Gobernador y Representante Legal "Evaluación y Ajuste del Plan de Vida Comunitario del Resguardo Indígena Tóez 2016-2019”.
} 
Además, según los datos aportados por un informante de la comunidad, en ella viven alrededor de 815 habitantes, de los cuales sólo hablan Nasa Yuwe el 25\% y además son mayores de 30 años.

Por otro lado, en cuanto a la vivienda, en el resguardo de Tóez, las viviendas familiares se extienden a lo largo del resguardo con una ocupación extensa en la que suelen residir más de una generación por hogar. Inseca Pacho (2016) en la evaluación realizada al "Plan de vida comunitario del resguardo indígena de Tóez 2016-2019”, pone de relieve la necesidad de ampliar el resguardo por falta de vivienda debido al aumento poblacional.

Hay que señalar, que además de las viviendas familiares, en el reguardo, existen algunos espacios comunitarios de encuentro en donde se realizan diferentes actividades socioculturales como la que aparece en las siguientes fotografías. Las instantáneas fueron tomadas por la autora de este artículo en la estancia realizada en el reguardo de Tóez entre febrero y marzo de 2019.

Figura 2: Espacio comunitario del resguardo de Tóez Caloro. Actividades de difusión del conocimiento.
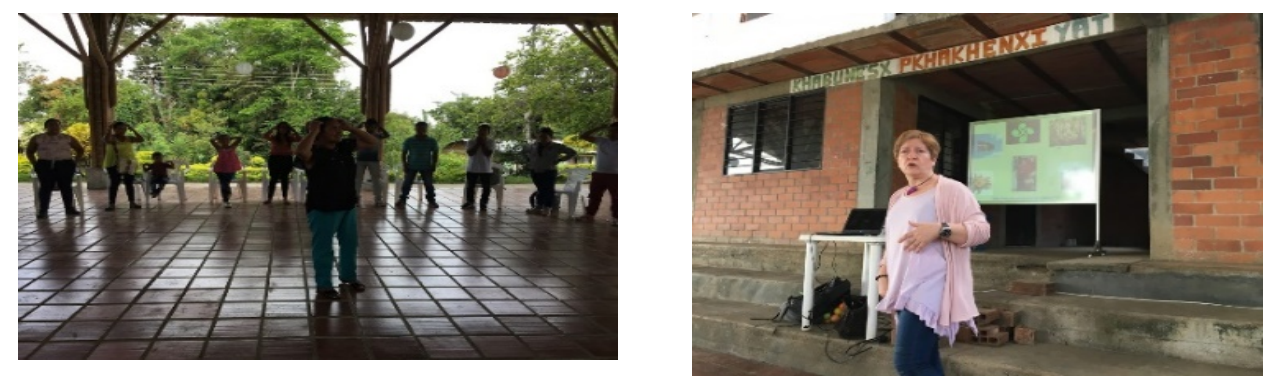

Igualmente, en este espacio colectivo se organizan actividades de índole comercial tradicional como el trueque de productos propios agrícolas. Asimismo, cabe señalar otro tipo de espacios, los deportivos, los dedicados a los jóvenes, los educativos y los comerciales, como las pequeñas tiendas de alimentación.

En cuanto a la economía, según el ONIC (2019 $\left.{ }^{13}\right)$, Organización Nacional Indígena de Colombia, la principal fuente de ingresos del pueblo Nasa es la agricultura, siendo el maíz

\footnotetext{
${ }^{13}$ Observatorio del Programa Presidencial de Derechos Humanos. (s.f.). (2019). Recuperado de https://www.onic.org.co/pueblos/2095-nasa
} 
el principal cultivo. El Ministerio de Interior de la República Colombiana así lo publica en el informe titulado “Caracterización del pueblo Nasa” realizado por el Observatorio del Programa Presidencial de Derechos Humanos en 2010:

Los Páez son un pueblo agrícola y su economía es básicamente de autoconsumo y se caracteriza por el policultivo en pequeña escala. Los ciclos vitales y las actividades cotidianas se encuentran determinadas por el trabajo de la tierra y por las fases agrícolas. Dentro de la mentalidad indígena, el ser Páez implica ser un buen trabajador de la tierra. El maíz se ha constituido en el eje central alrededor del cual se organiza la economía agrícola de los Nasa. Su gran importancia dentro de la vida económica y social, permite hablar de una verdadera "cultura del maíz”. La forma de trabajo de los Nasa ha sido históricamente a través del trabajo colectivo o "minga". La minga permite el aporte del trabajo de cada individuo en beneficio de la comunidad.

Otras fuentes de ingreso de las familias Nasa giran en torno a la ganadería, a la artesanía y a la migración estacionaria de miembros de la comunidad que trabajan como jornaleros en plantaciones de azúcar.

Siguiendo con el anteriormente citado informe de Inseca Pacho (2016), también se puede constatar el plan de mejora económico-ambiental en el que se identifican y priorizan los problemas de “desarrollo familiar y comunitario haciendo uso de los recursos naturales con sistemas propios de producción bajo un enfoque ambiental y sostenible mejorando la calidad de vida y así garantizar bienestar, armonía y equilibrio”.

Precisamente, El “Plan de vida comunitario del resguardo indígena de Tóez 2016-2019” es fundamental para comprender no solamente las necesidades económicas, sino también para identificar el enfoque con el que se quiere dar respuesta a las necesidades de la población del resguardo desde su cosmovisión cultural, creando un perfil de identidad propio acorde a su cultura. Este Plan abarca diferentes programas relativos a la organización socioeconómica, ahondando en la planeación, en la educación, en la familia, en lo económico-ambiental, en lo jurídico, en la salud, en la cultura y el deporte.

Como ya se ha señalado anteriormente, la siguiente sección de este artículo y en primer lugar, va a girar en torno a la conciencia y las actitudes sociolingüísticas del pueblo Nasa y al proyecto educativo como variables fundamentales en la transmisión de la lengua Nasa Yuwe. Para ello se ahondará en los dos centros educativos existentes en el reguardo de Tóez: la Institución Educativa-Etnoeducativo Tóez y el Nido lingüístico Buçxujx we'weka kwe'sx Yuwe’s. 


\subsection{Conciencia sociolingüística y actitud lingüística}

Etxebarria Arostegi (2002) señala que la conciencia sociolingüística refiere al conocimiento que los hablantes de una lengua tienen sobre las variantes o lenguas que integran el repertorio verbal de una comunidad, así como de los "parámetros valorativos" que se les otorgan. Ello implica que los hablantes de una lengua conocen ampliamente el vocabulario y registros de una lengua, y que a su vez son capaces de distinguir e identificar socialmente a los demás, a la vez de ser identificado por el resto. Es decir, la variable lingüística proporciona información sobre la situación social del hablante dentro de una comunidad.

Muestra de la conciencia sociolingüística Nasa, es la llamada que se hizo el día 21 de febrero 2019 en el reguardo de Caloto. Ese día, la comunidad Nasa celebró la conmemoración de la UNESCO, del día internacional de las lenguas nativas. Allí se concentraron tanto las autoridades indígenas así como las comunidades Nasa. En esta conmemoración se recordó la importancia de fortalecer la lengua materna en los distintos espacios del resguardo, resaltando la importancia del espacio familiar. Se hizo una llamada a los padres y madres como garantes de la transmisión lingüística y cultural, ya que se da más importancia a "la lengua prestada o Español que es de fuera”"

Esta preocupación por la recuperación de espacios tradicionales familiares de práctica de la lengua Nasa Yuwe, aporta indicios de la actitud individual sociolingüística de esta persona y de todas aquellas que estaban reunidas ese día con el propósito reivindicativo de la lengua.

Además de la conciencia sociolingüística, otro concepto a tener en cuenta es el de la actitud lingüística. Noción que se engloba en las actividades ligadas con la Política y

\footnotetext{
${ }^{14}$ Así lo manifestaba una mujer Nasa el 21 de febrero 2019, en la conmemoración del día internacional de las lenguas nativas. (2019). Recuperado de https://nasaacin.org/Nasa-Yuwe-la-base-fundamental-de-comunicacion-para-la-resistenciacultural-del-pueblo-Nasa/
} 
Planificación lingüística y que alude a conceptos de estandarización, autonomía, historicidad y vitalidad de una lengua (Fishman, 1972).

Es evidente que la preocupación del estado de vitalidad y futuro de la lengua Nasa Yuwe, tal y como se ha visto desde el inicio de este artículo, atraviesa diferentes organizaciones y entidades tanto de carácter internacional, estatal y de la propia comunidad Nasa. Desde estancias como la UNESCO, con la proclamación del “Año Internacional de las Lenguas Indígenas” en 2019, hasta las propias organizaciones indígenas como el ONIC, Organización Nacional Indígena de Colombia, el CRIC, Consejo Regional Indígena del Cauca y la ACIN Asociación de Cabildos Indígenas del Norte del Cauca.

Sin embargo, el riesgo de desaparición de las lenguas minorizadas no es una problemática joven. Desde hace varias décadas, ya se avisaba de este desvitalización. Un ejemplo de ello, es el Documento adoptado por la Reunión Internacional de Expertos sobre el programa de la UNESCO “Salvaguardia de las Lenguas en Peligro”, París, 10-12 de marzo de 2003. En él se advertía no solamente del grado de vitalidad de las lenguas y de la urgencia del trabajo de documentación, sino también se indicaban los principales factores de análisis en la evaluación de la vitalidad de una lengua. Muchos fueron los pasos dados, entre ellos la unificación del alfabeto Nasa Yuwe. Corrales en 2008, ya señalaba la madurez de los estudios lingüísticos de la lengua Nasa Yuwe:

En este mismo sentido, vale también mencionar la madurez que en estos momentos tienen los estudios lingüísticos de la lengua Nasa Yuwe, pues ya se cuenta con gran parte de la descripción y el análisis de las estructuras internas de la lengua. Sin esta condición era muy difícil, hace veinte años, haber propuesto un alfabeto unificado con altas consideraciones técnicas...

Etxebarria Arostegui (2000) apoyándose en investigadores como Fishman (1972) y su predecesor Stewart (1968), señala que estos investigadores, van más allá en el proceso de estandarización de un alfabeto, abarcando aspectos que van desde la creación literaria, hasta la científica, incluyendo variables sociales. Por lo tanto, además de las variables lingüísticas, hay que mencionar las variables sociales, variables sobre las que se va a regir está investigación y que van a permitir analizar cuál de los dos modelos educativos del resguardo de Tóez, Caloto, ayuda de forma más contundente en el proceso de revitalización de la lengua Nasa Yuwe. El origen histórico de los centros, su relación con los proyectos educativos institucionales vigentes, las etapas de educación que promueven, 
el perfil del profesorado con respecto al desarrollo y nivel de su competencia comunicativa en lengua Nasa Yuwe y por último los materiales y espacios del centro serán las variables a tener en cuenta.

A modo de ejemplo, al hablar de la conciencia lingüística del resguardo Nasa de Tóez, Caloto, Pachón y Correa (1997) señalan que en la cultura tradicional, el saber y la dirección de la comunidad se centran en la figura del anciano, quien establece las relaciones de autoridad dentro del seno familiar. Igualmente, se recurre a los ancianos como fuente de sabiduría y conocimiento, siendo el hogar y el fogón espacios principales en la transmisión de la lengua oral. Findji y Rojas (1985) en la investigación realizada en Jambaló, analizan la variable familia y lengua, llegando a la conclusión que es mayor el grado de conservación de la lengua en aquellas unidades familiares que se estructuran en torno a los abuelos, “la lengua, es una herramienta de comunicación familiar y por ende de la comunidad”.

En el área de la educación formal (Rojas, Perdomo, Corrales, 2011), la lengua Nasa Yuwe está prácticamente fuera del circuito del proceso de enseñanza-aprendizaje y su valoración social le concede un estatuto de invalidez para la creación y transmisión de conocimientos. Esta opinión choca con la actitud sociolingüista de las autoridades indígenas, quienes a través de todas sus organizaciones y proyectos, de los que se dará cuenta más abajo, pone de relieve la preocupación por el mantenimiento de la cosmovisión de la comunidad indígena Nasa, en la cual y siguiendo con el ejemplo anterior, la importancia de los mayores es primordial en el Proyecto Educativo Comunitario.

\subsection{Transmisión de la lengua en el ámbito escolar de Tóez}

En la actualidad dentro del resguardo de Tóez, conviven dos modelos educativos bien diferenciados: Buçxujx we’weka kwe’sx Yuwe’s o Nido lingüístico que abarca el periodo inicial a la enseñanza reglada y la Institución Educativa Etnoeducativo Tóez con una amplia oferta formativa. Aunque ambos se ubican en el mismo espacio geográfico y ambos aspiran a un modelo de educación propia, cada uno de ellos sigue un enfoque educativo muy diferenciado. Para poder comprender el marco pedagógico de estos dos centros educativos, conviene abordar de manera escueta el papel de la escuela oficial y la visión que de esta siempre han tenido los pueblos indígenas y en este caso el pueblo Nasa. 
2.6.1. Antecedentes educativos: los PEI, Proyecto Educativo Institucional y los PEC, Proyecto Educativo Comunitario.

Para las comunidades indígenas, la escuela oficial se ha situado siempre fuera de su cosmovisión, desarrollando su proceso de enseñanza-aprendizaje de forma ajena a su estructura social y cultural:

Inicialmente se abordó el papel histórico de la escuela oficial, percibida por las comunidades indígenas como una institución ajena a su estructura social y cultural. (Bolaños, G., Tattay, L. 2012)

El divorcio entre la escuela y el contexto sociolingüístico, político y cultural es una constante del aparato ideológico escolar y formativo al servicio del gobierno colombiano. La cultura reproductora de su lengua y cultura hegemónica y la no valoración de lo indígena, ha marginalizado la reproducción social y económica de las culturas y lenguas indígenas. El ninguneo de las autoridades políticas indígenas, la casi ausencia de las lenguas indígenas en el aparato escolar y formativo, las pedagogías no inclusivas, las metodologías autoritarias de los y las docentes y una forma de enseñanza externa al contexto social del alumnado, puso de relieve la necesidad de buscar alternativas que dieran el protagonismo a un proceso educativo que respondiera a las necesidades de las poblaciones indígenas. Igualmente, Bolaños, G., y Tattay, L. (2012) señalan que el hecho de que la educación estuviera también en manos de la Iglesia Católica, profundizaba esa brecha entre lo que se enseñaba, cómo se enseñaba y para quién se enseñaba.

El menosprecio al estudiantado y a su contexto de socialización indígena pone en marcha un proceso de apropiación de la formación dirigida a la comunidad y sus necesidades cosmogónicas. El objetivo es de mantener la visión propia de las comunidades indígenas en todas sus variables comunitarias, históricas, sociales, culturales, lingüísticas y económicas.

El Consejo Regional Indígena del Cauca (CRIC), en la celebración de su quinto congreso en 1978, decide poner en marcha un sistema de educación propio. Ello se debe, en primer lugar, a la necesidad de revitalizar las culturas y lenguas indígenas en proceso de severo debilitamiento y que acarrea como consecuencia la pérdida de sus identidades. Y en segundo término, debido a la insistencia del aparato hegemónico formativo en mantener el modelo socializador unidireccional colombiano que no cesa en su intento de seguir 
asimilando las culturas indígenas. De ahí, la búsqueda e investigación de alternativas a la subsistencia cultural indígena a través de un modelo que diera respuesta a las culturas, intereses y necesidades de los pueblos indígenas. Para ello se crean escuelas comunitarias, se postula una formación del profesorado bilingüe acorde a sus necesidades, se organiza el proyecto educativo comunitario y se encamina hacia un Sistema Educativo Indígena Propio (SEIP), con un desarrollo académico universitario, la universidad Autónoma Indígena Intercultural (UAIIN). Así, se concierta con el Estado colombiano el progreso y avance hacia una educación comunitaria, bilingüe e intercultural (no hay que olvidar la composición demográfica de los resguardos).

Además, hay que entender la búsqueda de este nuevo modelo educativo desde la resistencia, no sólo desde la formación, sino como una respuesta política hacia la apropiación de la tierra y hacia la toma de la escuela como parte de la comunidad haciéndola parte de su cotidianeidad (Bolaños, G., 2005). La escuela comunitaria es un modo de refuerzo de la comunidad.

Curiosamente, en 1994, la Ley General de Educación colombiana hace referencia a la etnoeducación, gracias al impulso de las comunidades indígenas y el PEI, Proyecto Educativo Institucional, concede una cierta autonomía organizativa a las instituciones. Sin embargo, este proyecto se mostró insuficiente para los proyectos comunitarios educativos que el CRIC llevaba impulsando desde hacía tiempo, como bien se acaba de mostrar. De la desconfianza hacia el PEI, se impulsa el PEC, Proyecto Educativo Comunitario, del que ya se ha mencionado anteriormente. A partir de esos momentos, se redimensionó lo institucional desde lo comunitario. Los PEC en los territorios indígenas están bajo la responsabilidad del cabildo local (Bolaños, G. 2005) y las comunidades que optaron inscribirse como PEI renunciaban al derecho a pronunciarse sobre la educación. Es decir y como señala esta misma autora, las comunidades que se inscribieron como PEC participan en la organización de la estrategia educativa del conjunto de las comunidades indígenas a través de su participación en el CETIC, Comité de Educación de los territorios Indígenas del Cauca. Por otro lado, los Centros Educativos Comunitarios Indígenas Bilingües (CECIB) se han dedicado y dedican a la profesionalización de los docentes a nivel bachillerato y universitario

El desarrollo de los Proyectos Educativos Comunitarios, no ha sido de manera uniforme en todos los resguardos Nasas e indígenas en general. Aunque el objetivo de este proyecto 
parte de la misma matriz de fortalecimiento de la comunidad, cada realidad sociolingüística ha derivado en los derroteros de su propia realidad local. Bolaños (2005) señala que a finales de la década de los noventa, alrededor de un $50 \%$ de las comunidades todavía no habían empezado a fomentar el Proyecto de Educación Comunitaria, pero sí habían alcanzado un nivel de acuerdo con el cabildo para hacerlo. Un 30\% había avanzado en su PEC organizando actividades con los cabildos y finalmente un 20\% habría logrado profundizar en el mismo.

Además, "El plan de Vida comunitario del resguardo" presenta y reestructura los programas que ya existen dentro del resguardo, entre los que se encuentra el educativo. En líneas generales, en el área de la educación, se trata de fortalecer los procesos de etnoeducación integral en el ámbito familiar comunitario e institucional. Abarca tanto la educación formal como informal, la educación para adultos, los convenios SENA (Servicio Nacional de Aprendizaje), la educación superior, la escuela Nasa Yuwe, los hogares infantiles, los sabedores ancestrales, las metodologías propias, la educación propia, la guardia indígena, el movimiento juvenil, las asambleas, las mingas comunitarias, los rituales mayores y los rituales intermedios.

Finalmente, la etnoeducación se presenta como eje fundamental en el proceso de enseñanza aprendizaje proponiendo una educación intercultural a través de un "Sistema de Educación Propio” (SEIP). En resumen, el Programa de Educación Bilingüe Intercultural, el Proyecto Educativo Comunitario (PEC) y los Centros Educativos Comunitarios Indígenas Bilingües (CECIB), forman el denominado Sistema Educativo Propio (SEIP).

Por ello, en el siguiente apartado de este artículo, referente a la metodología, conviene realizar una mirada a los dos modelos de educación existentes en la actualidad en el resguardo de Tóez, Caloto. Modelos que expresan, por un lado, la realidad institucional colombiana y su aproximación a la comunidad Nasa y por otro una educación alternativa y complementaria al proyecto comunitario indígena. Igualmente, según el enfoque teórico aportado por los autores mencionados Arostegui (2000) y Fishman (1972) “conciencia sociolingüística y actitud lingüística”, uno de estos dos modelos educativos, va a desarrollar una estructura más adecuada a la hora de la revitalización de la lengua y cultura Nasa en el resguardo de Tóez, Caloto. Por lo tanto la hipótesis que cabe formular es que Buçxujx we'weka kwe'sx Yuwe's o Nido lingüístico, representa el modelo 
educativo que responde directamente a las necesidades acuciantes de revitalización sociolingüística del Nasa Yuwe en este resguardo.

Así pues y antes de pasar a la metodología y teniendo en cuenta el enfoque teórico arriba mencionado, hay que recordar que las variables sociales a la hora de analizar cada uno de los centros educativos señalados son: su origen histórico, su relación con los proyectos educativos institucionales vigentes, las etapas de educación que promueven, el perfil del profesorado con respecto al desarrollo y nivel de su competencia comunicativa en lengua Nasa Yuwe y por último los materiales y espacios del centro.

\section{Metodología:}

Durante los meses de febrero y marzo 2019, la autora de este artículo, realizó una estancia de investigación en el resguardo Nasa de Tóez, Caloto. Durante este periodo de trabajo de campo, la recogida de información que permitió determinar cuál de los dos modelos educativos representados por dos centros educativos distintos existentes en el reguardo, responde mejor a las necesidades sociolingüísticas de revitalización, se realizó de manera cualitativa recurriendo a diversas técnicas de recogida de datos.

Así pues, teniendo en cuenta los objetivos iniciales, la hipótesis formulada así como el enfoque teórico señalado, cabe afirmar que la metodología cualitativa, es la que mejor se adecua a la recogida de información en el resguardo de Töez, Caloto, ya que permite recopilar datos en el mismo lugar, en el espacio geográfico directo donde se ubican los dos modelos educativos existentes. Igualmente, facilita la interacción directa con los propios protagonistas de los centros educativos mencionados. Para ello, se emplearon diferentes técnicas de recogida de datos. En primer lugar, se recurrió al análisis documental tanto sobre el contexto sociolingüístico y cultural del resguardo como sobre las dos instituciones educativas. Seguidamente, se llevó a cabo la observación directa del hecho educativo dentro del resguardo, siendo en algunos momentos concretos participativa (6 actividades dirigidas, tres de las cuales se realizaron en los espacios comunitarios y otras tres en el Buçxujx we’weka kwe’sx Yuwe’s o Nido lingüístico). Igualmente, se realizaron 4 entrevistas personales en profundidad, estructuradas y de respuesta amplia (una persona educadora de la Institución Educativa Etnoeducativo TóezCaloto y tres del Buçxujx we’weka kwe’sx Yuwe’s o Nido lingüístico). 
Igualmente, cabe señalar, que una vez terminada la estancia de investigación en el resguardo de Tóez, Caloto, las entrevistas personales con una de las docentes de la Institución Educativa Etnoeducativo Tóez-Caloto y con otra del Buçxujx we’weka kwe'sx Yuwe's o Nido lingüístico, se han mantenido en el tiempo durante todo el año 2019. Se han realizado un total de tres con cada una de ellas, usando diferentes formatos de comunicación, como el Skype y el correo electrónico. Estas conversaciones han girado en torno a preguntas cerradas de amplia respuesta.

En el siguiente apartado se muestran los resultados del estudio realizado sobre ambos centros y sus modelos educativos. Como se ha mencionado anteriormente, en cada uno se explicita su origen histórico, su relación con los proyectos educativos institucionales vigentes, las etapas de educación que promueven, el perfil del profesorado con respecto al desarrollo y nivel de su competencia comunicativa en lengua Nasa Yuwe y por último los materiales y espacios del centro.

\section{Resultados de investigación y conclusiones:}

\subsection{Institución Educativa Etnoeducativo Tóez-Caloto}

El origen de esta institución está ligado a la historia fundacional del resguardo en el que se ubica. Precisamente este año se ha rememorado que han pasado 25 años desde la avalancha ocasionada por el rio Páez en la zona de Tierradentro en 1994. Cabe recordar, que después de este trágico suceso que acabó con la vida de numerosos miembros de la comunidad Nasa, hubo que desplazar a los supervivientes a distintas zonas, siendo una de ellas Tóez Caloto, en donde en la actualidad se sitúa el resguardo.

En 1994, esta Institución inicia su tarea educadora partiendo del objetivo de evocar lo que la comunidad perdió en su lugar de origen. En este nuevo espacio de formación, se pretendía de alguna manera, recuperar los proyectos de desarrollo local y regional y en segundo lugar, fortalecer elementos culturales y políticos propios, que desde la cosmovisión Nasa, salvaguardaran la identidad y autonomía Nasa.

En el Proyecto Educativo Comunitario de la Institución participan los líderes de la comunidad, el cabildo indígena, docentes, estudiantes e instituciones del sector educativo y productivo. Entre los diferentes estamentos "se concretan unos principios, unos objetivos y metas, un plan de estudios, una programación curricular y unas actividades de 
tipo comunitario y de gestión y administración que permiten iniciar parcialmente, a fines de 1994". ${ }^{15}$

Igualmente, la Institución Educativa Etnoeducativo de Tóez-Caloto, se define de carácter mixto y de modalidad agroecológica. Además, tiene como visión a largo plazo, de cara al 2022, ser pionera en innovación de procesos pedagógicos, económicos, culturales y ambientales. Todo ello enmarcado en el Proyecto Educativo Intercultural Comunitario PEIC. La Institución abarca estudios de preescolar, básica primaria, básica secundaria, media técnica y escuela intercultural para jóvenes y adultos (EIIJ)

En la actualidad, en la Institución hay 278 estudiantes matriculados, lo que supone 18 aulas de clase. También, cuenta con 17 profesoras y profesores, de los cuales 7 son Nasas. De estos 7 docentes Nasa, 4 poseen la competencia comunicativa en lengua Nasa Yuwe y española y sólo dos se dedican a la enseñanza de esta lengua y cultura. Además, las relaciones laborales y sociales entre ellos, dentro del marco de la Institución, se desarrollan en Nasa Yuwe.

Tabla 2. Profesorado de la Institución Educativa Etnoeducativo Tóez-Caloto

\begin{tabular}{|c|c|c|}
\hline Profesorado total de la Institución & 17 & $100 \%$ \\
\hline Profesorado Nasa & 7 & $41,17 \%$ \\
\hline Profesorado que habla la lengua Nasa Yuwe & 4 & $23 \%$ \\
\hline $\begin{array}{l}\text { Profesorado que comunica entre sí en Nasa } \\
\text { Yuwe }\end{array}$ & 4 & $23 \%$ \\
\hline Profesorado que enseña la lengua Nasa Yuwe & 2 & $11,7 \%$ \\
\hline
\end{tabular}

Por otro lado, la lengua Nasa Yuwe, está presente en la Institución como asignatura obligatoria en primaria y secundaria, siendo su periodicidad de impartición de dos horas por semana. Durante este período formativo, se inicia al alumnado a hablar y escribir en Nasa Yuwe e igualmente se desarrollan programas de reivindicación cultural y artística. El número de niños, niñas y jóvenes competentes en la lengua (que tienen el Nasa Yuwe como lengua materna) es muy escaso, situándose en un porcentaje bajísimo, no llegando

${ }^{15}$ Portal de información de la Institución Educativa Etnoeducativo Tóez-Caloto (s.f.). (2019). Recuperado de http://www.ieetoezcaloto.edu.co/index.php/institucion/historia 
a 12 (siempre según los datos procurados por una informante de la comunidad). Además, este alumnado viene de otros resguardos.

En cuanto a la dirección de la Institución, se puede decir que hasta este año 2019, ha mantenido una actitud un tanto distante ${ }^{16}$ con respecto a la lengua vernácula y la cultura del pueblo Nasa. El sentimiento de alejamiento, pasividad y falta de compromiso con lo local, se repite en el resto de la plantilla profesoral. Estos indicios de resistencia pasiva a la presencia del Nasa Yuwe como lengua inclusiva de todo tipo de conocimientos y no solamente de los tradicionales, es precisamente, una barrera invisible pero constante en la revitalización de la lengua Nasa Yuwe en el resguardo de Toéz, Caloto y más concretamente el espacio lingüístico escolar .

Sin embargo, recientemente, debido precisamente al cambio habido en la dirección del centro, "parece" ${ }^{17}$ que se inicia un periodo de articulación educativo pionero en este resguardo. Se va a dar un paso adelante en el proceso de enseñanza-aprendizaje de la Institución. Por primera vez, la lengua Nasa Yuwe va a dejar de estar restringida a las horas de docencia de lengua y cultura para pasar a impregnar otros conocimientos y espacios aledaños. Es decir, la lengua Nasa Yuwe se va a convertir en herramienta de comunicación integral al abarcar espacios de conocimientos que hasta la "casi” actualidad habían sido reservados a la lengua hegemónica española. Por primera vez, dentro de la Institución, se va a iniciar a corto plazo, la formación de un grupo de transición con alumnos y alumnas de 5 años que va a iniciar este periodo educativo. El hecho de dotar de nuevos instrumentos comunicativos de educación al Nasa Yuwe, a través de un proceso de enseñanza-aprendizaje global capaz de vehicular todo tipo de contenidos teóricos y prácticos, proporciona una serie de pasos en el proceso de vitalización de la lengua. ¿De dónde viene esta iniciativa?

\footnotetext{
${ }^{16}$ Siempre según el grupo de personas entrevistadas en el resguardo de Tóez Caloto, durante los meses de febrero, marzo y noviembre 2019.

${ }^{17}$ En estos momentos se encuentra en periodo de negociación la apertura de una línea en lengua Nasa Yuwe dentro de la Institución. Información aportada por miembros de la comunidad del resguardo (2019).
} 


\subsection{Buçxujx we’weka kwe’sx Yuwe’s o Nido lingüístico}

Dentro de la comunidad del resguardo de Tóez, la preocupación por el estado de la lengua y su necesidad de revitalizarla subraya la importancia de promocionar el aprendizaje del Nasa Yuwe. Como ya se ha mencionado anteriormente, "El Plan de Vida Comunitario” profundiza en este sentido fortaleciendo aquellas iniciativas que analicen, estudien y pongan en práctica actividades de revitalización lingüística. En este contexto, un grupo de mujeres Nasa procedentes de Tierradentro ve la necesidad de promover y producir nuevas iniciativas pedagógicas que profundicen en la recuperación lingüística de la lengua Nasa Yuwe. Iniciativas que irán poniendo en marcha y que van a culminar, entre otros muchos proyectos, en el Buçxujx we’weka kwe'sx Yuwe’s o Nido lingüístico o escuela de prescolar. Hay que entender que el "Nido" o escuela de preescolar nace auspiciada por “La casa de la lengua-Kwe`sx we`wenxi yat”. Esta Institución se plantea como objetivo activar y estimular el estudio y aprendizaje de la lengua Nasa Yuwe para todos los miembros de la comunidad. Igualmente promueve el uso de la lengua en los diferentes espacios del resguardo poniendo el acento en los procesos culturales e identitarios:

...busca dinamizar el proceso de aprendizaje de la lengua Nasa entre todos los miembros de la comunidad, desde y en los diferentes espacios comunitarios, así como potencializar los procesos culturales que garanticen la pervivencia de la identidad y el pensamiento Nasa, en el diario vivir de este resguardo... (Corrales 2018).

Además, La casa de la lengua-Kwe`sx we`wenxi yat, es consciente de que para fomentar la reproducción de la lengua hay que dotarla de un "estatus” y “prestigio” social que lleve a sus hablantes y neo hablantes a practicarla. Para ello, promueve actividades intergeneracionales que incluyan e interrelacionen a los Nasa Yuwe hablantes con otros miembros de la comunidad, todo ello, en un intento de inculcar a las familias la necesidad de la transmisión lingüística y de reconducir la idea que poseen los jóvenes de que la lengua no es importante ni necesaria.

Por otro lado, La casa de la lengua-Kwe`sx we`wenxi yat, también se plantea como objetivo, formar Nasa Yuwe hablantes que cumplan la función de multiplicadores de la lengua a través de un diplomado. 
Asimismo, la escasez de material didáctico y pedagógico y la necesidad de producirlo, es otro de los objetivos de La casa de la lengua-Kwe`sx we`wenxi yat y por último, pone de relieve, la importancia de aprovechar los espacios políticos y sociales para desarrollar la conciencia colectiva sobre la importancia del uso de la lengua.

La casa de la lengua-Kwe`sx we`wenxi yat aunque es una Institución de carácter privado, cuenta con el apoyo de la Asociación de Cabildos Indígenas del Norte del Cauca (ACIN), especialmente de su Tejido de Educación y de su Hilo Nasa Yuwe (Corrales, 2018):

La coordinadora de la Kwe'sx we’wenxi yat (Casa de la lengua), Yaneth Maritza Pacho, agradeció a las Autoridades del Cabildo y a la Universidad del Cauca por su compromiso y apoyo en los procesos de fortalecimiento de la lengua ancestral. También felicitó a quienes hicieron parte del diplomado y cumplieron con las tareas para culminar adecuadamente este nivel de formación (Universidad del Cauca, 2018). ${ }^{18}$

Así, La Casa de la lengua-Kwe`sx we`wenxi yat se convierte en instrumento y herramienta para la reproducción de la cosmovisión cultural Nasa y de su lengua Nasa Yuwe. En este entorno de vías de extinción lingüística en el resguardo de Tóez Caloto, se pone de relieve el rol del centro escolar oficial denominado Institución Educativa Etnoeducativo Tóez-Caloto. El adoctrinamiento cultural Nasa promovido por la Institución se muestra insuficiente en su proceso de escolarización y de enseñanzaaprendizaje y en su presencia en el ámbito público. De esta insuficiencia, tanto en la formación de la infancia como de la juventud y de la necesidad de extrapolación de la lengua Nasa Yuwe al ámbito social, se desarrolla la idea de un nido lingüístico que comience su andadura con los más jóvenes de la comunidad.

Por lo tanto, el Nido lingüístico Buçxujx we’weka kwe’sx Yuwe’s, es una iniciativa pedagógica formativa anclada en la cosmovisión de la cultura Nasa y externalizada a través de la competencia comunicativa oral y escrita en lengua Nasa Yuwe. Este

\footnotetext{
${ }^{18}$ Noticias de la Universidad del Cauca. (s.f.). (2019. Recuperado de http://www.unicauca.edu.co/versionP/noticias/proyecci\%C3\%B3n-social/unicauca-clausuradiplomado-lectura-y-escritura-de-la-lengua-Nasa-Yuwe
} 
enraizamiento en la cultura Nasa enlaza con la identidad del pueblo indígena y con la revitalización de su vehículo de transmisión lingüística.

Buçxujx we'weka kwe’sx Yuwe’s o Nido lingüístico promueve un proceso educativo en la formación inicial de la infancia, estando previsto el uso del Nasa Yuwe como herramienta de transmisión de conocimientos y que las criaturas se formen con el Nasa Yuwe como primera lengua y como bilingües competentes desde la educación inicial, desde la semilla (Corrales, 2018).

En la actualidad, Buçxujx we’weka kwe’sx Yuwe’s o Nido lingüístico cuenta con 13 niñas y niños de uno a cuatro años. Según Janeth Maritza Pacho Hurtado (2019), una de las promotoras del proyecto, la demanda de solicitudes presentadas para la escolarización en este modelo educativo ha ido aumentando, sin embargo, la infraestructura limita a este número la cantidad de alumnado escolarizado. La imposibilidad de poder atender a todas las familias que optan por este modelo educativo propio acentúa la falta de medios económicos Buçxujx we’weka kwe’sx Yuwe’s o del Nido lingüístico.

Además, cabe destacar, que la existencia de esto modelo y su pragmatismo frente a la cultura propia ha ido recuperando mentalidades de la comunidad que se mostraban poco receptivas hacia el proceso de enseñanza-aprendizaje del mismo. Los resultados obtenidos con los niños y niñas, pone relieve la eficacia de esta alternativa frente al otro modelo de la Institución. En una conversación mantenida con Janeth Maritza Pacho Hurtado (2019), afirmaba que todos los infantes entienden y que para los tres años, los niñas y niños de Buçxujx we’weka kwe’sx Yuwe’s o Nido lingüístico ya son capaces de comunicar oralmente, expresándose de manera natural en Nasa Yuwe. En este mismo sentido, se manifestaba otra de las informantes, Stella Hurtado Mulcue (2019). Esta profesora de la Institución Educativa Etnoeducativo Tóez-Caloto, reconoce la competencia comunicativa del alumnado del Nido lingüístico, ya que es ella quien se hace cargo de los niños y niñas que terminan el ciclo formativo en el Nido lingüístico y pasan a la Institución. Cabe señalar, que debido a la juventud del Nido lingüístico, no existen por el momento investigaciones documentadas sobre el nivel de la competencia comunicativa oral de los niños y niñas de este centro. Sin embargo, después de asistir a varias sesiones con el alumnado del mismo, se puede afirmar que el nivel de comprensión oral del alumnado permite a las docentes poder llevar a buen término las actividades 
programadas tanto dentro del Buçxujx we’weka kwe’sx Yuwe’s o Nido lingüístico como en las actividades externas al mismo.

Igualmente, Janeth Maritza Pacho Hurtado (2019), añade que es una pena que estos niños y niñas una vez que finalicen esta etapa educativa no formal al pasar a la Institución formal abandonen los conocimientos ya adquiridos. Subsanar esta pérdida es uno de los objetivos principales de las responsables tanto de La casa de la Lengua como del Nido lingüístico. De ahí su interés en articular su etapa educativa con la de la Institución.

Por otro lado, en cuanto a los locales del Buçxujx we'weka kwe'sx Yuwe's o Nido lingüístico, se localizan dentro del resguardo y más concretamente dentro del espacio geográfico de una de las mujeres impulsoras del proyecto educativo. El local o habitabilidad en el que se desarrolla el proceso educativo es de propiedad privada al que se le da un usufructo público:
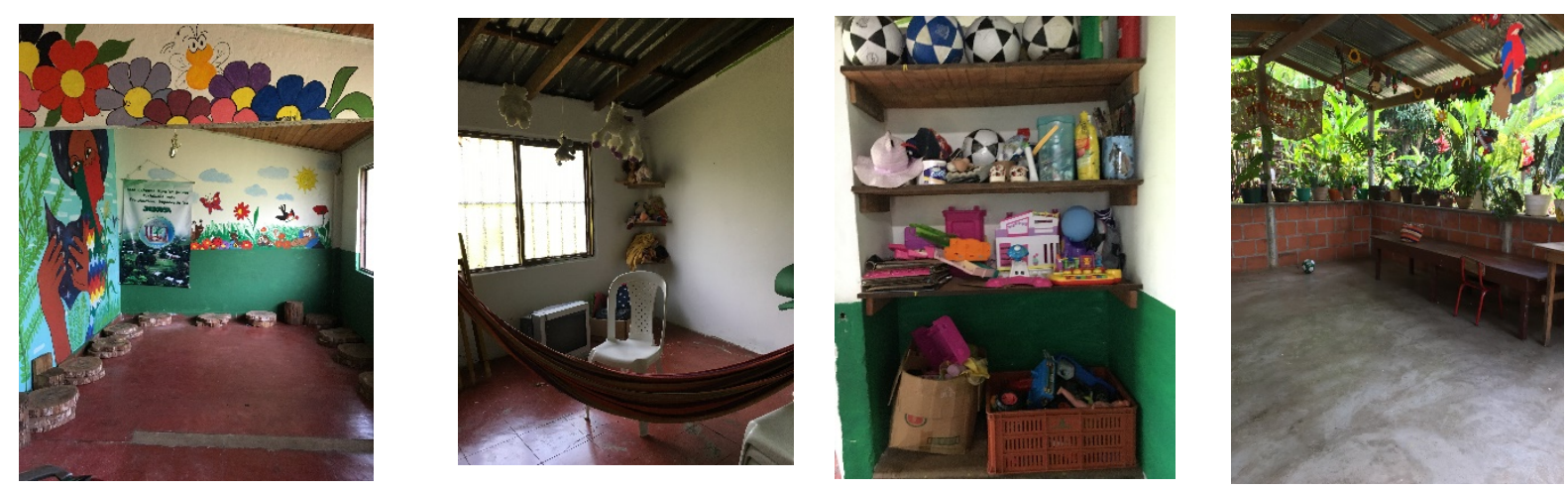

Fgura 5. Espacios y materiales de Buçxujx we’weka kwe’sx Yuwe’s o Nido lingüístico.

Evidentemente, el hecho de que los locales escolares se encuentren dentro de la cédula de habitabilidad de una de las creadoras de este proyecto formativo, pone en evidencia las limitaciones que ello supone de cara a la expansión, promoción y ejecución del mismo.

En relación con la falta de espacio, hay que remarcar también otro tipo de dificultades. Así por ejemplo, la dificultad de encontrar docentes con la competencia comunicativa en lengua Nasa Yuwe, la carencia de materiales adecuados a la edad del alumnado y la falta acusada de medios económicos para hacer frente a todas las necesidades: espacios, material, salarios de las trabajadoras y docentes, etc. 
Sin embargo, a pesar de todas estas trabas, poco a poco la presencia del Buçxujx we’weka kwe’sx Yuwe's o Nido lingüístico ha ido derribando resistencias dentro de la comunidad con respecto a su modelo. Entre las muchas de ellas, se van a citar dos, por ser quizás las más exponenciales. Una, el hecho de que los padres y madres apuesten por un modelo que es permitido pero que no “está legalizado” y que además se desarrolla en lengua no hegemónica española. Y dos, el hecho de que sus hijas e hijos se inserten en un proceso de enseñanza-aprendizaje sin saber si van a tener continuidad o no.

Precisamente al hablar sobre la continuidad de estudios, las organizadoras de La casa de la lengua-Kwe`sx we`wenxi yat y de Buçxujx we’weka kwe’sx Yuwe’s o Nido lingüístico, puestas en contacto con la nueva dirección de la Institución Educativa Etnoeducativo Tóez-Caloto, han logrado que a corto término se inicie una vía educativa continuista con los propósitos de Buçxujx we’weka kwe’sx Yuwe’s o Nido lingüístico. Por lo tanto, estos niños y niñas competentes en comunicación Nasa Yuwe podrán, inicialmente, continuar el periodo de transición en el mismo modelo que han cursado hasta entones. Es decir un modelo socioeducativo, sociocultural y lingüístico acorde a la identidad del pueblo Nasa.

Sin embargo, a medida que los infantes de Buçxujx we’weka kwe'sx Yuwe's o Nido lingüístico vayan cumpliendo años y tengan que cambiar de nivel y etapa escolar, evidencia la necesidad de seguir progresando en la apertura de esa nueva vía en la Institución. De ahí la conveniencia de establecer un puente entre ambos modelos y sus currículos o bien seguir adelante con el modelo propio de Buçxujx we'weka kwe'sx Yuwe’s o Nido lingüístico abarcando las necesidades de la infancia a medida que vaya cumpliendo años y abriendo aulas de cursos superiores que permitan avanzar en su proceso de enseñanza-aprendizaje.

Para terminar, a pesar de la no muy favorable situación de Buçxujx we’weka kwe’sx Yuwe’s o Nido lingüístico, este sigue implacablemente adelante en su misión y visión sabiendo que en otras realidades culturales ha sido posible revitalizar, con mayor o menor incidencia una lengua y cultura, tal es el caso de la lengua vasca o euskera y su modelo de ikastola o escuela. 


\subsection{Conclusiones}

Tanto en el inicio de este artículo como al final del mismo, hay que evocar que este año la UNESCO ha proclamado el 2019 como “Año Internacional de las Lenguas Indígenas”. Por ello, cabe recordar a los diferentes estamentos políticos, sociales, económicos, etcétera, que intervienen en los procesos educativos colombianos que todavía la variable “indigenista” está muy lejos de los mismos. Sí, es cierto, que ha habido un breve avance “teórico” en los cambios de leyes y que el movimiento indígena ha dado grandes pasos organizativos y reivindicativos. Sin embargo, algunos académicos colombianos como por ejemplo Pachón, C. X. (1997), Rojas Curieux (2005), Aldemar Inseca Pacho, J. (2016) y Corrales (2018), señalan que todavía queda mucho que investigar en el largo proceso de la revitalización de las lenguas indígenas en general y de la lengua Nasa Yuwe en particular. Además, como se ha podido constatar a lo largo del artículo, la vitalización de la lengua Nasa Yuwe es una necesidad que vas más allá de poder verbalizar en una lengua. Esta es más que un instrumento de comunicación, es una herramienta, un útil de identidad que abarca tanto la historia como la cultura de un pueblo. Es la cosmovisión, el saber hacer, su universo cultural y social.

Por otro lado, el proceso de revitalización del Nasa Yuwe se desarrolla de forma desigual en los diferentes resguardos Nasa. Tal y como señalan Arostegui (2000) y Fishman (1972) el estado de vitalidad de una lengua minorizada va a depender en otros muchos factores, de la conciencia sociolingüística y de la actitud lingüística de cada pueblo y cultura.

Igualmente en el caso del Nasa Yuwe, la conciencia sociolingüística y la actitud lingüística toma cada día más relevancia, quedando así manifestado, por ejemplo, en la unificación del alfabeto Nasa Yuwe, en el aumento de investigaciones y de producciones académicas en torno a la cuestión, en la implicación de las instituciones indígenas Nasa, en el interés de la comunidad en recuperar espacios de comunicación, entre otros.

En esta misma línea y una vez analizados los dos modelos educativos vigentes en el resguardo de Tóez, Caloto, se puede afirmar que el Buçxujx we’weka kwe’sx Yuwe’s o Nido lingüístico, ahonda de manera más fehaciente en la revitalización de la lengua Nasa Yuwe al mostrar una conciencia sociolingüística y una actitud lingüística más acorde con las necesidades de la cultura Nasa. Dicho de otra manera, Buçxujx we'weka kwe'sx Yuwe’s o Nido lingüístico es un claro exponente de la conciencia sociolingüística y actitud lingüística, en el que un grupo de mujeres toman la iniciativa de revitalizar el Nasa 
Yuwe en el espacio geográfico privado de una de ellas. Paradójicamente espacio privado de uso colectivo. Lugar de encuentro de unas familias sociolingüísticamente concienciadas que reivindican a través de sus hijos e hijas algo que es suyo y a la vez colectivo, el querer desarrollarse y vivir conforme a su identidad. El coraje, valentía y formación de este grupo de mujeres que han creado un modelo educativo "no institucional” ha eliminado barreras dentro del proceso de enseñanza-aprendizaje clásico institucional. Igualmente ha trabajado para modificar los esquemas mentales de los miembros de su comunidad con respecto a la "apreciación y valoración” de su propia lengua y cultura tratando de impulsar la actitud lingüística y conciencia sociolingüística del resguardo de Tóez, Caloto.

Las variables sociales desarrolladas anteriormente en torno a los dos modelos educativos, evidencian que el Buçxujx we’weka kwe'sx Yuwe's o Nido lingüístico propone una alternativa educativa más acorde con las expectativas revitalizadoras de la lengua Nasa Yuwe en el resguardo de Tóez, Caloto.

Por último y para terminar, conviene señalar que a pesar de los obstáculos económicos, de carencia de profesorado competente en lengua Nasa Yuwe, de infraestructuras y de más necesidades, La casa de la lengua- Kwe`sx we`wenxi yat y el Buçxujx we’weka kwe'sx Yuwe’s o Nido lingüístico, siguen “el intento revitalizador educativo propio” aspirando a que su alumnado pueda tener “continuidad formativa” en la Institución Educativa Etnoeducativo Tóez-Caloto. 


\section{Referencias bibliográficas}

Aldemar Inseca Pacho, J. (2016). Evaluación y ajuste del plan de vida comunitario del resguardo indígena Tóez 2016-2019. Autoridad Tradicional del Resguardo Indígena de Tóez, municipio de Caloto. Tóez. Caloto, Colombia: Resolución 040 del 10 de abril de 2003.NIT 817007143-0.

Austin, Peter. (2008). One thousand languages: living, endangered, and lost. California: University of California Press.

Bolaños, G., Tatta, L. (2012). La educación propia: una realidad de resistencia educativa y cultural de los pueblos. Educación y ciudad, no22.Enero-Junio 2012 ISSn 0123-0425 p.p 45-56.

Corrales Carvajal, M.H. (2011). Hacia una historia social de la escritura alfabética entre el pueblo Nasa ¿Por qué y para qué lee y escribe el pueblo Nasa? (Tesis doctoral) Universidad de Antioquia. Medellín.

Chaparro Rojas, J.F. (2011). Tipología del bilingüismo en jambaló, cartografía de la situación actual. (Trabajo fin de master). Bogotá d.c.: Universidad nacional de Colombia.

Etxebarria, M. (2000). Principios y fundamentos de Sociolingüística. Bilbo: UPV/EHU.

Findji, M.T, Rojas. J.M. (1985). Territorio, economía y sociedad Paez. Cali: Universidad del Valle.

García Choque. F, (2018). Manual instructivo para la implementación del PEI Intercultural. Programa Educación Intercultural Bilingüe. Colombia: Ministerio de Educación de Colombia.

Gordon, Raymond G., Jr. (Ed.). (2005). Ethnologue: Languages of the world (15th ed.) Dallas, TX: SIL International. ISBN 1-55671-159-X

Kowi, A. (2005). Identidad lingüística de los pueblos indígenas de la Región Andina. Quito: editorial Abya Yala.

Landaburu, Jon. (2005). Las lenguas indígenas de Colombia: presentación y estado del arte. Centre d'Études des Langues Indigènes d'Amérique - CNR. AMERINDIA n 29/30

Ministerio de Cultura de Colombia. (2014). Prosperidad para todos. Circulo de la Palabra Lenguas Nativas. Colombia.

Ministerio de Cultura. (2015). República de Colombia. 200 años. Cultura es Independencia. Nasa (Paez), la gente del agua. Bogotá.

Pachón, C. X. (1997). Lenguas amerindias.Condiciones socio-lingüísticas en Colombia. Colombia: SantaFé. 
Rojas Curieux, Tt., Nieves Oviedo, R., Yule Yatacue, Marcos. (1991). Estudios Gramaticales de la Lengua Paez (Nasa Yuwe). Descripciones. Bogotá: Colciencias Universidad de los Andes,

Rojas Curieux, T., Esteban Díaz Montenegro. (2014). Kwe'sx Nasa Yuwete we'wnxi paylatewe'sx Léxico del Nasa Yuwe de La Paila Naya. Colombia,

Rojas Curiex, T. (1998). La lengua páez, una visión de su Gramática, Bogotá: Ministerio de Cultura.

\section{Páginas web:}

Alfabeto Nasa. (s.f.). (2019). Recuperado http://diccNasaYuwe.blogspot.com/

Betancourt, S. (2013). Recuperado de https://www.mininterior.gov.co/content/resguardoindigena

Centro de Educación Capacitación e Investigación para el Desarrollo Integral de la Comunidad -CECIDIC (2019) Recuperado de http://www.cecidic.edu.co/Direccionamiento estrategico/article/quienes-somos

Contexto sociolingüístico de Tóez Caloto: la dispersión Nasa, pluralidad de comuneros, la localización laboral, la educación en lengua Nasa Yuwe. (s.f.). (2019) Recuperado de https://Nasaacin.org/tag/tejido-de-educacion/

Corporación Nasa Kiwe. (2019) Recuperado de

http://www.Nasakiwe.gov.co/la-corporacion/creacion-cnk/

Corrales, M.H. (2018). Lenguas ancestrales de Colombia. Entre acallamientos y sobrevivencias, educaciones y escuelas.

Recuperado de http://www.ehu.es/ikastorratza/20_alea/1.pdf.

Cosmovisión pueblo Nasa. (s.f.). (2019) Recuperado de

http://www.terapianeural.com/publicaciones/39-articulos-y-publicaciones/medicina-y-

humanismo/118-cuerpo-y-cosmos-en-el-rito-paez-vision-problematica

DAE 2018. (s.f.). (2019). Recuperado de

https://www.dane.gov.co/files/censo2018/informacion-tecnica/presentaciones-

territorio/190814-CNPV-presentacion-Resultados-etnicos-Cauca.pdf

DAE. Grupos étnicos. (s.f.). (2019). Recuperado de

https://www.dane.gov.co/index.php/estadisticas-por-tema/demografia-y-

poblacion/grupos-etnicos

Diccionario Nasa Yuwe. (s.f.). (2019). Recuperado de

http://diccNasaYuwe.blogspot.com/ 
Desde arriba y por abajo construyendo el alfabeto Nasa. La experiencia de la unificación del alfabeto de la lengua páez (Nasa Yuwe) en el Departamento del Cauca. (2019). Recuperado de http://documentacion.ideam.gov.co/openbiblio/bvirtual/002885/areas/minorias/contenid /paez.htm\#4.7.4\%20LA\%20LENGUA

Institución etnoeducativa. (s.f.). (2019). Recuperado de http://ieetnoeducativodetoez.blogspot.com/

ONIC. (s.f.). (2019). Recuperado de https://www.onic.org.co/pueblos/2095-Nasa

Proyectos Nasa. (2919). Recuperado de

http://www.proyectoNasa.org/index.php?option=com_content\&view=article\&id=20\&It $\underline{\text { emid }=217}$

Permanent Forum on Indigenous Issues. (2017). Recuperado de

https://www.un.org/development/desa/indigenouspeoples/unpfii-sessions-2/sixteenthsession.html

Una mirada al Nasa yube. (s.f.). (2019) Recuperado de

https://www.academia.edu/12760057/Una_mirada_al_habla_Nasa_Yuwe_de_Novirao.

Noviraote_Nasa_Yuwe_wewenxis_thegna

UNESCO. (s.f.) (2019) Recuperado de

https://uploadsssl.webflow.com/5d2499e6a5dbeca3c357d762/5d9caaaacedb8f04ef2e66

1d_ES_UNESCO-A.pdf

UNICEF: La Educación Intercultural Bilingüe. (s.f.). (2019). Recuperado de https://www.unicef.es/prensa/unicef-presenta-el-atlas-sociolinguistico-de-pueblosindigenas-en-america-latina 